\title{
Morinda citrifoliia $L$. as a renewable raw material for surface active agent
}

\author{
Trismawati ${ }^{1, *}$ and Wikanaji $\mathrm{D}^{2}$ \\ ${ }^{1}$ Mechanical Engeneering, Universitas Panca Marga, 67271 Probolinggo, Indonesia. \\ ${ }^{2}$ Scientist, Independence Researcher, 67217 Probolinggo, Indonesia.
}

\begin{abstract}
Surface active agent (surfactant) is a substance or a blend of substances that lower the surface tension or interfacial tension between two liquids. It contains both hydrophobic groups (its tail) and hydrophilic groups (its head). Surfactants lower the surface tension of a liquid by spreading spontaneously over its surface. To understand its suitability for raw material of surfactant, the seed of Morinda citrifolia $\mathrm{L}$ is extracted for its fatty acid contents and evaluated for its spreading ability into other liquid. Its fatty acid contents are analyzed by FTIR and GCMS method and its spreading ability is evaluated by its diffusion characteristic using Helle Shaw Cell. From FTIR it is known that the oil seed of Morinda citrifolia has functional groups suitable for the hydrophobic part of surfactant. From GCMS it is known that the seed of Morinda citrifolia L contains huge amount of poly unsaturated fatty acid (PUFA) of C19:2 suitable for the hydrophobic part of surfactant. From diffusion experiment using Hele Shaw Cell it is known that the spreading ability of its PUFA in oil phase is approaching its commercial synthetic surfactant has but it is not in water phase.
\end{abstract}

\section{Introduction}

Morinda citrifolia L. has been used in folk medicine over 2000 years ago. Many researches have been done to explore its other beneficial values. Aqueous extract of Morinda citrifolia L. has mild antibacterial activity and significant antioxidant, anti-nociceptive, and antiinflammatory effects [1]. Other studies have reported that the extract of Morinda citrifolia leaf contains polyphenols component that significantly has biological effect in folk medicine [2]. Anthraquinone extraction from the root of Morinda citrifolia has also been studied [3]. Seed oil of Morinda citrifolia has been extracted and evaluated for its nutritional quality and safety, it may be useful as a new source of vegetable oil [4]. Seed oil of Morinda citrifolia L. has been used as surfactant for flotation deinking [5].

Sodium dodecyl sulfate " $\mathrm{Na} \mathrm{C}_{12} \mathrm{H}_{25} \mathrm{SO}_{4}$ ", sodium oleate " $\mathrm{C}_{17} \mathrm{H}_{33} \mathrm{COO}-\mathrm{Na}$ ", and sodium benzene dodecyl sulfate" $\mathrm{C}_{18} \mathrm{H}_{31} \mathrm{Na} \mathrm{O}_{4} \mathrm{~S}$ " are some examples of fatty acid based of surfactant, some of them have been evaluated in deinking flotation [6]. Other surfactants are synthesized by polymerization process followed by ethoxylation to increase the hydrophilic character. Its functional groups are modified as sulfate, sulfonate, phosphate,

\footnotetext{
* Corresponding author: trismawati@upm.ac.id
} 
and carboxylate. It may also be modified as primary, secondary and tertiary amines or quaternary ammonium cationic.

Surfactants are not used only in detergent, medicine, pharmaceutical but also in deinking process, waste water treatment and oil recovery. Surfactants are used in deinking flotation to facilitate the interaction between ink (oil based) and water. Surfactant flooding for enhance oil recovery (EOR) has ability to increase the displacement efficiency by lowering the interfacial tension between oil and water and mobilizing the residual oil [7], this because the effect of adsorption of surfactant onto the reservoir rock is eliminated.

When two phases of fluids keep in contact, the less viscous fluid will penetrate into other by diffusion process until phase equilibrium is achieved. Research concerning about this has been done using Hele Shaw cell apparatus $[8,9,10]$. The viscous fingering instability of miscible flow displacements in a homogeneous porous media is also examined in the case involving reversible chemical reactions between the fluids [10], and miscible viscous fingering involving viscosity increase by a chemical reaction with moderate Damköhler number [11].

In this research, fatty acid from Morinda citrifolia L is used as surfactant, the importance characteristic of surfactant such as unsaturated bond of hydrocarbon, hydrophilic functional group of fatty acid, and good penetration of surfactant to other fluids through micro diffusion is examined.

\section{Experimental}

Research was conducted in our private laboratory in coordination with Chemical Laboratory of Brawijaya, and Chemical Laboratory of State University of Malang. Seed oil of Morinda citrifolia is extracted by soxhlet extraction for 4, 5, 6, 7, 8 hours. Extracted fatty acid is concentrated by vacuum evaporator. The concentrated fatty acid then analyzed using FTIR dan GCMS to know its functional group and composition.
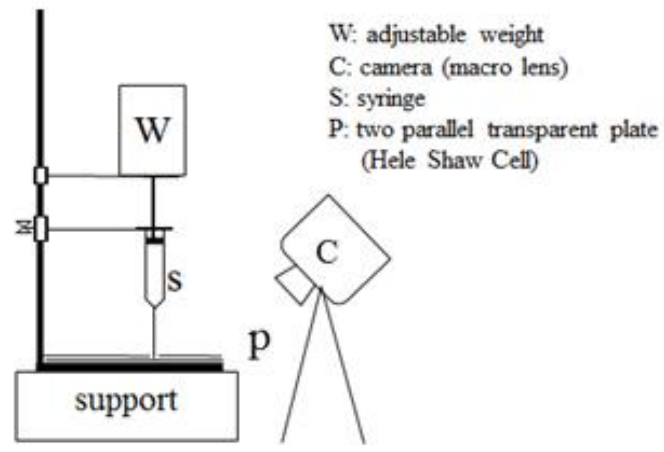

Fig. 1. Hele Shaw cells apparatus

The phases interaction between the extracted fatty acid and other fluids (in this case oil base dyes) is examined using Hele Shaw cells apparatus to know how well it diffusion character if compared with synthetic commercial surfactant and palm oil.

\section{Result and Discussion}

From the FTIR analysis it is known that seed oil of Morinda citrifolia L. is a hydrocarbon molecule that identified has carboxylate functional group (Figure 2). 


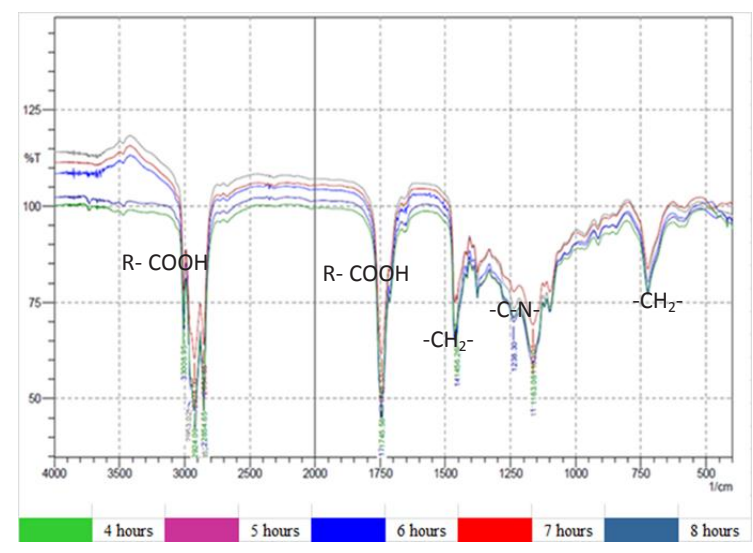

Fig. 2. FTIR analysis results of fatty acid of Morinda citrifolia L

From GCMS analysis it is known that in graph (a) line 1 occupied less amount of total ion chromatogram (TIC) and line 2 occupied high amount of TIC (around 96,5 \%). Line 1 is methyl butanoate as shown in graph (b), and Line 2 is 9, 12 Octadecadienoic Acid as shown in graph (c).

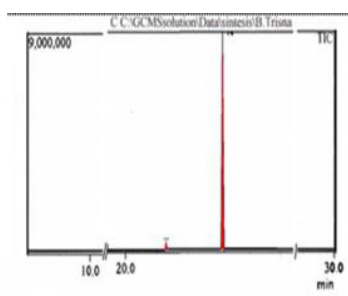

(a)

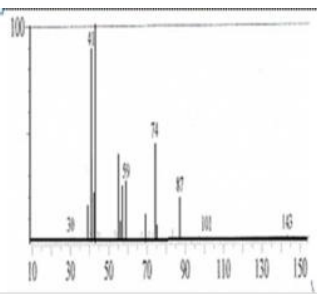

(b)

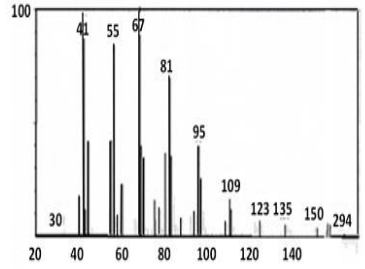

(c)

Fig. 3. Example of GCMS result (for 6 hours extraction time).

From this analysis it is known that seed oil of Morinda citrifolia L. is a fatty acid of long chain hydrocarbon that has two double bonds. So it is belong to Poly unsaturated fatty acid (PUFA). This PUFA can be used as the raw material of surfactant and it is supported by other experimental result [6].

To understand how well its characteristic in doing phase contact with oil and water, a micro diffusion studies is perform in Helle Shaw cells as shown in Figure 4.

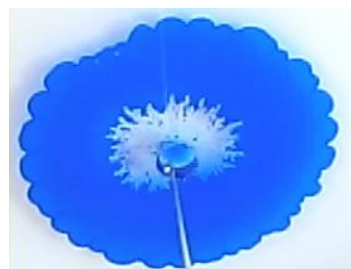

Surfactant 30 second

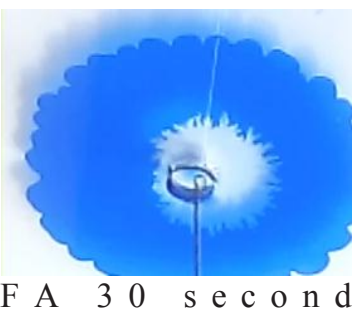

F A 30 s e c o n d

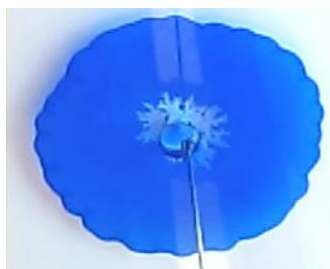

Palm Oil 30 second 


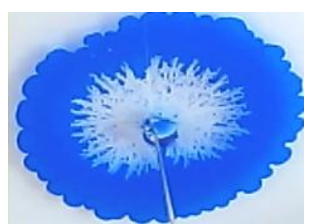

Surfactant 60 second

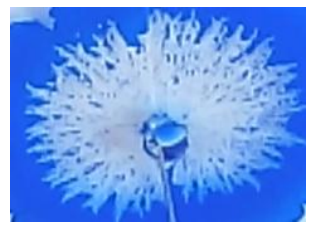

Surfactant 1 minute 30 second

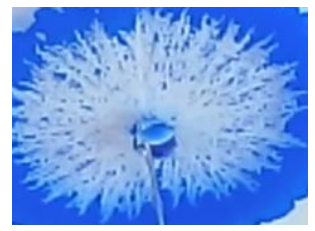

Surfactant 120 second

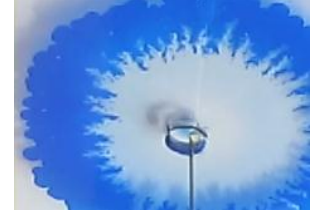

FA 60 second

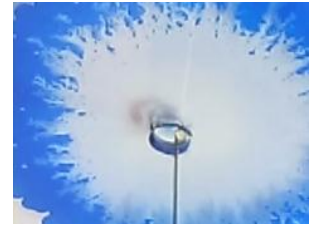

FA 1 minute 30 second

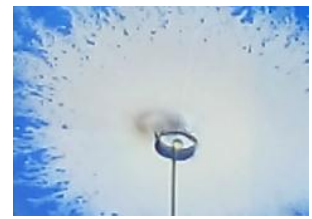

FA 120 second

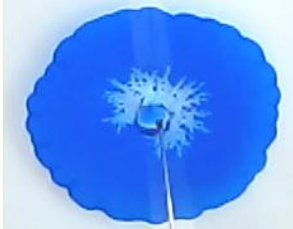

Palm Oil 60 second

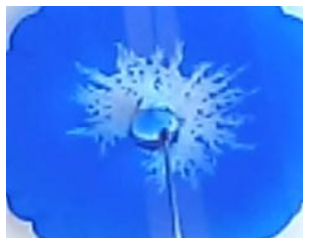

Palm Oil 1 minute 30

second

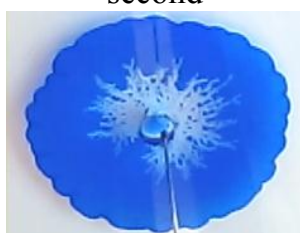

Palm Oil 120 second

Fig. 4. Micro diffusion of surfactant, fatty acid (FA) and Palm oil in oil base blue dyes

The micro diffusion is perform and is compared with other micro diffusion of other substances. Micro diffusion of fatty acid is compared with micro diffusion of commercial surfactant and palm oil. It is known that the commercial surfactant has molecular structure of $\mathrm{R}-\mathrm{NH}-\mathrm{CH}_{2}-\mathrm{OH}$ or $\mathrm{R}-\mathrm{NH}-\mathrm{CH}_{2}-\mathrm{COOH}$ and Palm oil has $\mathrm{CH}_{3}-\left(\mathrm{CH}_{2}\right)_{14}-$ $\mathrm{COOH}$ molecular structure or $\mathrm{C} 16: 0$. The number of $\mathrm{R}$ is varies and it has been mixed between saturated and unsaturated fatty acid C16, C17, C18 or C19 and mostly has been ethoxylated (number of ethylene oxide molecules is inserted) to increase its hydrophilic properties

In Figure 4, it can be seen clearly that the micro diffusion of fatty acid of Morinda citrifolia L is better than the commercial surfactant does, and far better than the palm oil does. It is prove that fatty acid of Morinda citrifolia $\mathrm{L}$ has better character in doing its job to penetrate into the ink molecule than commercial surfactant and palm oil does. It can be inferred that C18:2 structure of fatty of Morinda citrifolia has suitable properties to be used as surfactant for being able to penetrate into the oil phase when compared with C16:0 structure of fatty acid of palm oil. This fingering pattern of diffusion is supported by other researches $[9,11]$.

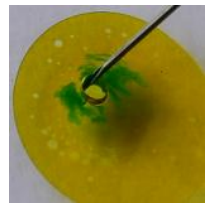

(a)

After $15 \mathrm{sec}$ injection of water

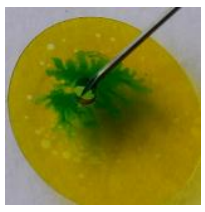

(b)

After $20 \mathrm{sec}$ injection of water

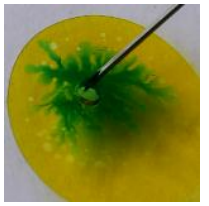

(c)

After $25 \mathrm{sec}$ injection of water

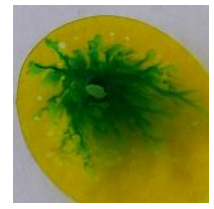

(d)

After $30 \mathrm{sec}$ injection of water

Fig. 5. Micro diffusion between Commercial surfactant and water. Yellow is surfactant and green is water. 
From Figure 5 it is clearly seen surfactant and water has a good interaction. It is proves that the hydrophilic properties of commercial surfactant is good. Fingering is recorded for 15 seconds of injection of water and it is more pronounce in every 5 second of interval time. With ongoing time the fingering pattern seem pronounce, the middle part of the finger seem darker in colour (assumed as a hill that has high concentration of pure water) and the rear part seem lighter in colour (assumed as a valey that has low concentration of pure water, in this part the water distribute it self in order to penetrate into the surfactant body). The alley and hill pattern are figureout. This finding is also supported by other researches $[9,11]$.

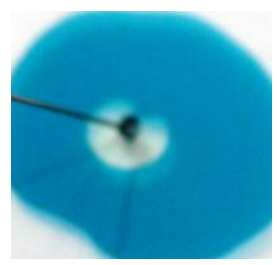

(a)

After $15 \mathrm{sec}$ injection of water

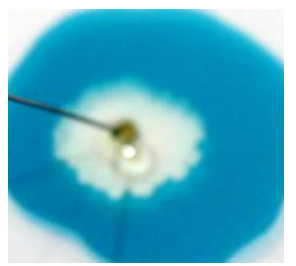

(b)

After $30 \mathrm{sec}$ injection of water

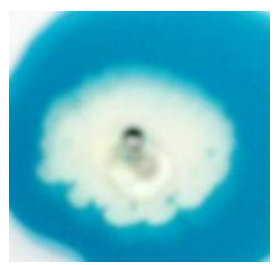

(c)

After $60 \mathrm{sec}$ injection of water

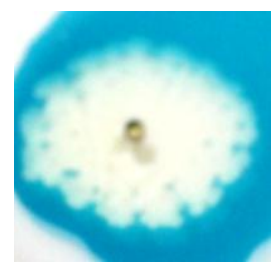

(d)

After $90 \mathrm{sec}$

injection of water

Fig. 6. Micro diffusion between fatty acid of Morinda citrifolia L. and water. Blue is fatty acid and white is water.

Fatty acid was injected first follow by water injection. It is clearly seen that fingering was seem happened after 10 second injection of water (but this is not the real fingering except the flow of water try to find the way out from the surrounding fatty acid). This pseudo fingering was more pronounce in every 10 second of interval time. The alley and hill pattern in this case cannot be observed.

\section{Conclusion}

From the above results it is prove that:

1. Fatty acid of Morinda citrifolia L. has good properties for being used as raw material of surfactant in case of the interaction with oil. It properties is approaching or a little bit better than commercial surfactant has. In case of palm oil, the interaction with oil is poorer than both of them.

2. In case of interaction with water, fatty acid has poorer properties than commercial surfactant has, because its molecular structure has not been modified to increase its hydrophilic properties.

3. Seed oil of Morinda citrifolia L. can be used as surfactant by modification in its molecular structure (i.e by ethoxylation).

\section{References}

1. R. S. Mairim, J Med Food 14 (2011)

2. Y. T. Yin, K. H. Swee, Y. L. Jia, W. H. Chun, P. Y. Chin, Food Chemistry 120 (2010)

3. P. Boonchai, G. Motonobu, S. Mitsuru, A. Thitiporn, P. Prasert, S. Artiwan, J. of Supercritical Fluids 37 (2006)

4. J. Brett, I. West, International Journal of Food Science and Technology, 43 (2008) 
5. Trismawati, I. N. G. Wardana, N. Hamidi, M. N. Sasongko, AJChE, 16 (2016)

6. C.A. Costa, J. Rubio, Minerals Engineering, 18 (2005)

7. B. Achinta, T. Kumar, O. Keka, M. Ajay, Applied Surface Science 284 (2013)

8. Trismawati, I. N. G. Wardana, N. Hamidi, M. N. Sasongko, Tenside and Surfactant Detergents, 54 (2017)

9. N. Yuichiro, B. Si-Kyun,m K, Yoshihito, T. Yutaka, Physical Review E 77 (2008)

10. H. Alhaumaude, J. Azaiez, Proceedings of the World Congress on Engineering, vol III, WCE, London, U. K. July 3 - 5 (2013).

11. N. Yuichiro, K. Yusuke, K. Yoshihito, T. Yutaka, Physics of Fluids 23 (2011) 